\title{
Outcome of Management of 5 Cases of Abdominal Pregnancies
}

\author{
Augustine Ochigbo Ojabo ${ }^{1^{*}}$, Samuel Kuma Hembah-Hilekaan1, Onyemocho Audu², \\ Ehiagwina Andrew Okoh ${ }^{1}$, Nwoyi Otu Oka1 \\ ${ }^{1}$ Department of Obstetrics and Gynaecology, College of Health Sciences, Benue State University, Makurdi, Nigeria \\ ${ }^{2}$ Department of Epidemiology and Community Health, College of Health Sciences, Benue State University, \\ Makurdi, Nigeria \\ Email: austinojabo@yahoo.co.uk
}

Received 20 June 2015; accepted 9 July 2015; published 15 July 2015

Copyright (C) 2015 by authors and OALib.

This work is licensed under the Creative Commons Attribution International License (CC BY). http://creativecommons.org/licenses/by/4.0/

\section{(c) (i) Open Access}

\begin{abstract}
Abdominal pregnancies are rare; however, they are still frequently missed pre-operatively. This presents diagnostic and treatment dilemma especially in resource-constrained settings where CT-scan and MRI are not readily available for accurate diagnosis. Five cases of abdominal pregnancies were managed over an eighteen-year period. In 2 cases, the condition was diagnosed preoperatively. The age range of the patients was from 32 to 36 years with a mean of 32.4 years. All 5 patients recovered fully; 4 required at least 2 units of blood transfusion; the placenta was left behind in 1 case; 1 required methotrexate to enhance placental resorption. One patient had recurrent intestinal obstruction and eventually had laparotomy and release of thick bands of adhesion. Two patients had conceived at least once each following treatment. Abdominal pregnancies present serious diagnostic and management dilemma especially in low resource settings. A high index of suspicion and prompt laparotomy can be life-saving. There is little information known about future fertility after abdominal pregnancy.
\end{abstract}

\section{Keywords}

Abdominal Pregnancy, Laparotomy, Placenta, Blood Transfusion

Subject Areas: Global Health, Gynecology \& Obstetrics

\section{Introduction}

Abdominal pregnancy is a rare form of ectopic pregnancy in which the implantation takes place in the peritoneal cavity outside the fallopian tube [1].

\footnotetext{
*Corresponding author.
}

How to cite this paper: Ojabo, A.O., Hembah-Hilekaan, S.K., Audu, O., Okoh, E.A. and Oka, N.O. (2015) Outcome of Management of 5 Cases of Abdominal Pregnancies. Open Access Library Journal, 2: e1643. 
Despite the use of ultrasound, the diagnosis of abdominal pregnancy is usually missed during antenatal care. It occurs either as a result of tubal abortion or rupture, known as secondary abdominal pregnancy, or more rarely, as a direct implantation on the peritoneum, with normal fallopian tubes, normal ovaries, or without tubal fistula, known as primary abdominal pregnancy [2].

Implantations can also occur on omentum, vital organs, or large vessels. These pregnancies can go undetected until an advanced gestational age and often result in severe hemorrhage [3].

There is a high maternal morbidity and mortality associated with abdominal pregnancy. Its management depends on the gestational age and site where the placenta is attached [4]-[6].

Majority of patients who present with abdominal pregnancies are of low parity and desire future fertility [7]. The literature is scanty on fertility following successful management of abdominal pregnancies.

\section{Methodology}

This is a retrospective review of 5 cases of abdominal pregnancy managed by laparotomy over an 18-year period (1996-2014).

Verbal consent was obtained from the patients before their data was included in the study.

Information relating to socio-demographic characteristics, mode of management, outcome of management and future fertility were retrieved from the patients case notes.

Data analysis was by simple proportions and chi-square test of association.

\section{Results}

There were 5 cases over the study period. The age range was between 22 and 36 years, average 32.4 years. All the women were married. Parity range from 1 - 4, with an average of 2.6. Eighty percent had at least post primary education. Only $40 \%$ had the correct diagnosis made pre-operatively. None had MRI or CT-Scan for preoperative diagnosis. At laparotomy, all the fetuses were dead (see Figure 1); in 4 cases, the placenta was attached to the intestine and/or omentum. In one case, the placenta was attached to the right broad ligament.

In 4 of the cases (80\%), the placenta were necrotic and easily detached from the structure to which they were adherent (see Figure 2). In one case, the placenta was morbidly adherent to the mesocolon and removing it was considered too risky for haemorrhage, so it was left in-situ (Table 1).

All the patients had blood transfusions with fresh whole blood, ranging from 2 pints to 6 pints, with an average of 3.5 units. All the patients had uneventful post-operative recovery except the patient who had the placenta left in-situ. She was given $200 \mathrm{mg}$ methotrexate once to enhance resorption of the placenta and membranes.

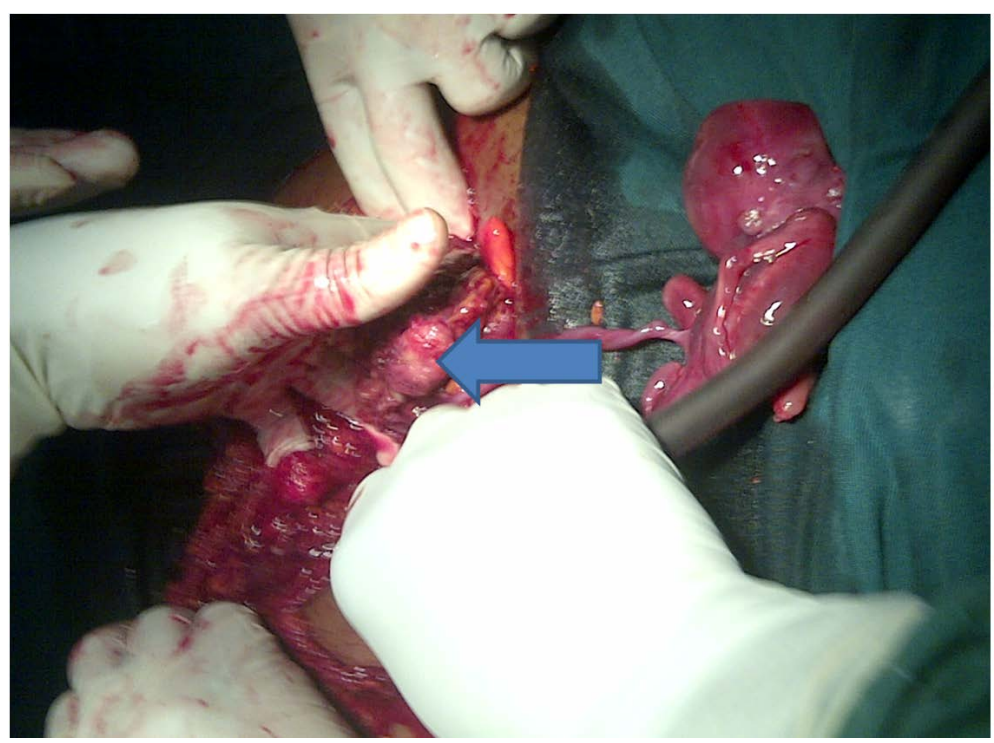

Figure 1. Fetus with placenta in-situ in one case of abdominal pregnancy. Intact uterus (arrowed). 


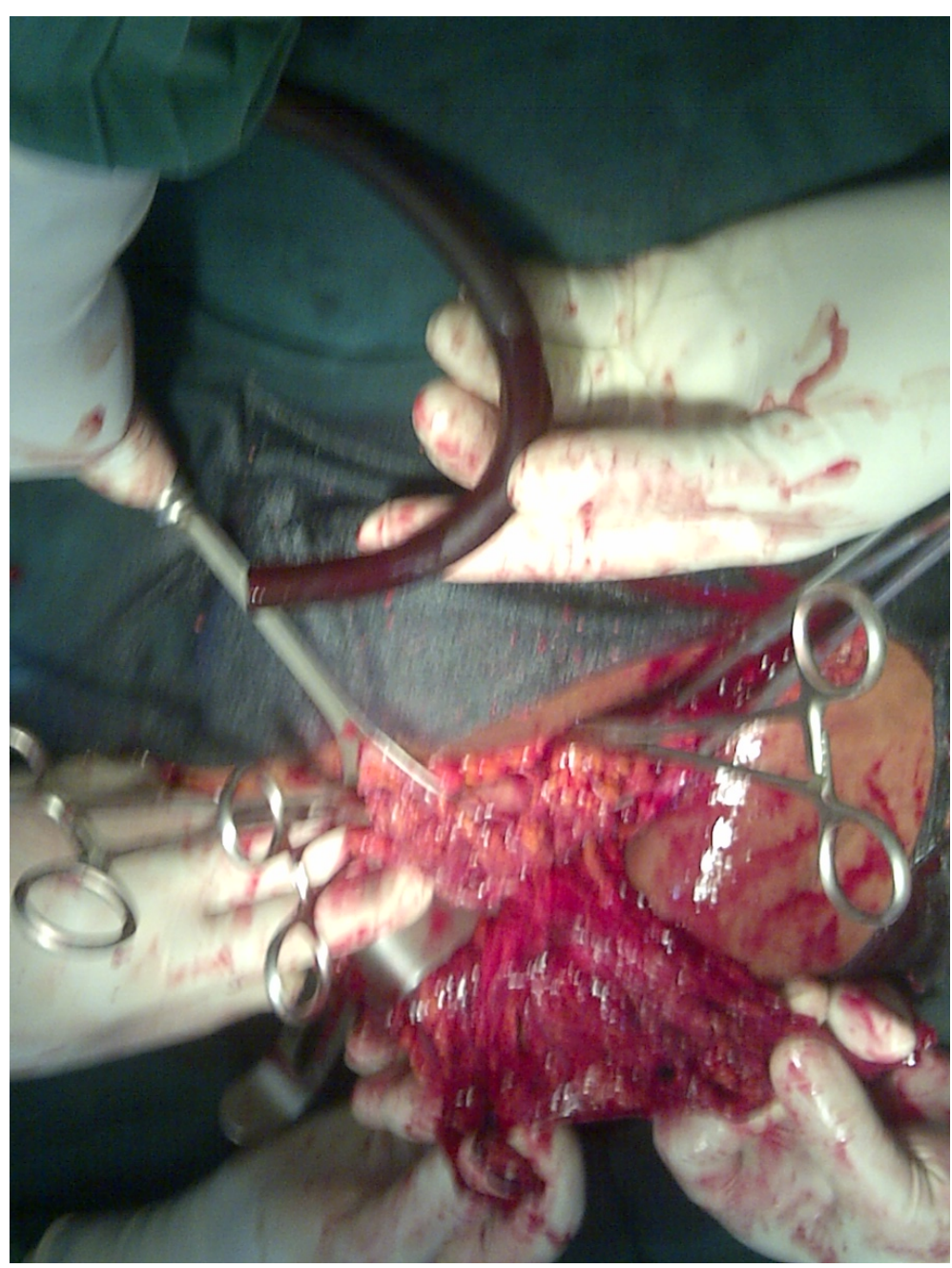

Figure 2. Placenta been separated from attachment to abdominal viscera.

Average length of hospital stay was 10 days. On follow-up, 4 patients had no complaints but one patient had abdominal pain with distension. She was readmitted and managed for intestinal obstruction with nil per os (NPO), ivf, antibiotics and analgesics, laparotomy and separation of adhesion bands.

All the patients were desirous of further fertility. Over the period of follow-up extending between 3 to 18 years, only two patients had conceived. One patient had an uneventful pregnancy and delivered a life male baby at term. The second patient had a miscarriage at 3 months in the first pregnancy and a live male baby in the second pregnancy following term uneventful pregnancy (Table 1).

The remaining 3 patients did not conceive during the period of follow-up. The aetiology of subfertility in those patients was tubal factor.

\section{Discussion}

Abdominal pregnancy may account for up to $1.4 \%$ of ectopic pregnancies [8] [9].

In Nigeria, abdominal pregnancy accounts for 34 per 100,000 pregnancies [10] probably due to the increased incidence of pelvic inflammatory disease.

It is a very rare form of ectopic pregnancy accounting for 1/10 000 deliveries in developed countries and between 3.4/10,000 (Nigeria) to 1/2256 (Congo) in sub-Saharan African countries. Despite this important difference of incidences between poor and rich countries, abdominal pregnancy represents almost the same proportions of ectopic pregnancies in both settings: 1.5\% (Gabon) and 1.4\% (United States of America) respectively [11]. 
Table 1. Socio-demographic variables and outcome of management.

\begin{tabular}{|c|c|c|c|c|}
\hline a. & VARIABLE & & FREQUENCY & MEAN \\
\hline & \multirow{3}{*}{ Age } & $15-25$ & 1 & \multirow{4}{*}{32.4 years } \\
\hline & & $26-30$ & 1 & \\
\hline & & $31-35$ & 3 & \\
\hline & & $0-1$ & 1 & \\
\hline \multirow[t]{2}{*}{ b. } & Parity & $2-3$ & 3 & \multirow[t]{2}{*}{2.6} \\
\hline & & $4-5$ & 1 & \\
\hline \multirow[t]{4}{*}{ c. } & Level of education & & & \\
\hline & Primary school & 1 & & \\
\hline & Secondary sch. & 3 & & \\
\hline & Tertiary & 1 & & \\
\hline \multirow[t]{2}{*}{ d. } & Pre-operative diagnosis-diagnosed & 2 & & \\
\hline & Undiagnosed & 3 & & \\
\hline \multirow[t]{3}{*}{ e. } & Placental management & & & \\
\hline & Removed & 4 & & \\
\hline & Left in situ & 1 & & \\
\hline \multirow[t]{4}{*}{ f. } & Blood transfusion (pints) & & & \\
\hline & $1-2$ & 3 & & \\
\hline & $3-4$ & 1 & & \\
\hline & $\geq 5$ & 1 & & 3.5 \\
\hline \multirow[t]{3}{*}{ g. } & Hospital admission & & & \\
\hline & 2 weeks & 3 & & \\
\hline & $\geq 3$ weeks & 2 & & \\
\hline \multirow[t]{3}{*}{ h. } & Desire for future fertility & & & \\
\hline & Desirous of future fertility & 5 & & \\
\hline & Not desirous of future of fertility & 0 & & \\
\hline \multirow[t]{4}{*}{ i. } & Fertility after abnormal pregnancy & & & \\
\hline & 2 women conceived over $>15$ yrs follow-up & $3 x$ & & \\
\hline & Cumulative pregnancy rate & 3 & & \\
\hline & Live birth rate & $2 / 3$ & & \\
\hline \multirow[t]{3}{*}{ j. } & Long term complication & & & \\
\hline & Intestinal obstruction & 1 & & \\
\hline & Recurrent abdominal pain & 1 & & \\
\hline
\end{tabular}

It is often associated with high maternal mortality because of late presentation, missed preoperative diagnosis and difficult intra-operative and post-operative management [12] [13].

In this study, majority of the pre-operative diagnosis was missed. This is due to low index of suspicion, nonspecific clinical features and unavailability of advanced diagnostic imaging modalities such as CT-scan and MRI [14] (Table 1).

The clinical features usually include abdominal pain, nausea, vomiting, painful fetal movements, and less frequently, vaginal bleeding. None of the patients in this study presented with vaginal bleeding. This is not un- 
usual as vaginal bleeding is not a frequent mode of presentation of abdominal pregnancy [9] [14] [15].

In 1942, Studdiford outlined his criteria for abdominal pregnancy: 1) normal bilateral fallopian tubes and ovaries; 2) absence of uteroperitoneal fistula; or 3) presence of a pregnancy related to the peritoneal surface exclusively [15].

Today, the diagnosis of abdominal pregnancy is often made using ultrasound and X-ray. The classic ultrasound finding is the absence of myometrial tissue between the bladder and pregnancy [16].

Elevated serum alpha-fetoprotein has also been associated with abdominal pregnancy [17].

Diagnostic laparoscopy may also be of value when there is a doubt about pregnancy location [18].

In some cases, the diagnosis is not made until at laparotomy as was the case in majority of the patients in this study. Magnetic resonance imaging (MRI) holds promise as a diagnostic tool [19].

The patients are of low parity by Nigerian standards where the average fertility rate is 5.7 [20]. Other studies have shown a range of parity from 0 to 9 [7]. Thus, abdominal pregnancy can occur in women irrespective of their parity.

The average age of the women in this study was 32.4. In a similar study from Ghana, the average age was 30.4 [7].

Frequently, these pregnancies are encountered with a viable fetus, which complicates their management [21].

In this study, none of the fetuses was viable. This is due to the relatively low gestational age and late diagnosis usually following fetal death [22]. However, the site of implantation and availability of vascular supply are believed to be factors that may influence the possibility of fetal survival [21], meanwhile, some authors in Nigeria have described salvaging live fetuses from abdominal pregnancies [22].

The decision to remove or not to remove the placenta can be a difficult one to make. The decision made can also determine whether the patient survives or not. In this study, the placenta was left in-situ in only one case. This was because of the perceived high risk of haemorrhage due to its attachment to the mesocolon. In the other cases, the placentae were removed as they were found to have separated from the underlying structures, perhaps due to the fact that the fetal death had occurred several days before laparotomy was performed.

In the patient in whom the placenta was left behind, methotrexate was given in order to enhance its resorption [23].

This patient also had a complicated post-operative course marked by abdominal pain and distension, recurrent intestinal obstruction and eventually, laparotomy for release of intra-abdominal adhesions (Table 1).

Other management modalities aimed at reducing blood loss are, ligation of placental blood supply, ligation of the umbilical cord and expectant management, arterial embolization, or methotrexate used to facilitate involution [21].

However, leaving the placenta in situ may lead to further complications such as infection, secondary hemorrhage, or intestinal obstruction, residual bleeding, pre-eclampsia (which may all necessitate further surgery) and failure to breast feed due to placental hormones [24]-[26].

Laparoscopy has been used in the treatment of some early abdominal pregnancies [27].

This conservative management should only be undertaken when the abdominal pregnancy has implanted on a less vascular surface. Primary methotrexate has been attempted for early gestations with minimal success [28] [29].

All the patients had blood transfusion due to haemorrhage which usually accompanies attempts to remove the placenta especially when they are attached to highly vascular structures. However in this study, the average amount of blood transfused was relatively low at 3.5 units. In some studies, the average units of blood transfused was 5 pints [30] [31].

This may be due to the long interval of time between fetal death and time of laparotomy. However, this also increases the risk of haemorrhage from DIC [32] [33].

There is little information known about future fertility after abdominal pregnancy.

Fertility following successful management of abdominal pregnancy is an important consideration as our society place a very high premium on large family size. The total fertility rate in (TFR) Nigeria is 5.7 [34].

Only two women had conceived during a follow-up period spanning over 15 years. In a study from SouthEastern Nigeria, even though the majority of the women were lost to follow-up over the years; of the five women that were successfully followed up, only two (40\%) had subsequent childbirth [35].

The main factors implicated in the resulting infertility were tubal in nature. This could be due to formation of peritubal, peri-ovarian, perifimbrial adhesions, and pre-existing tubal disease that resulted in the abdominal 
pregnancy in the first instance.

Outcome with abdominal pregnancy can be good for the baby and mother, Lampe described an abdominal pregnancy baby and her mother who were well more than 22 years after surgery [36].

\section{Conclusions}

Abdominal pregnancy can be successfully managed with little or no long-term complication for the mother. A high index of suspicion, accurate pre-operative diagnosis and availability of blood transfusion services can further improve the outcome.

More studies with higher sample size and longer follow-up are required to study fertility after abdominal pregnancy.

\section{References}

[1] Bertrand, G. (2009) Imaging in the Management of Abdominal Pregnancy: A Case Report and Review of the Literature. Journal of Obstetrics and Gynaecology Canada, 31, 57-62.

[2] Tutuncu, L. and Mungen, E. (2005) Does Previous Cesarean Delivery Increase the Risk of Ectopic Pregnancy? Perinatal J, 13, 105-109.

[3] Fisch, B., Peled, Y., Kaplan, B., Zehavi, S. and Neri, A. (1996) Abdominal Pregnancy Following in Vitro Fertilization in a Patient with Previous Bilateral Salpingectomy. Obstetrics \& Gynecology, 8, 642-643. http://dx.doi.org/10.1016/0029-7844(96)00213-X

[4] Varma, R., Mascarenhas, R. and Jame, D. (2003) Successful Outcome of Advanced Abdominal Pregnancy with Exclusive Omental Insertion. Ultrasound in Obstetrics \& Gynecology, 21, 192-194. http://dx.doi.org/10.1002/uog.25

[5] Onan, M.A., Turp, A.B., Saltik, A., Akyurek, N., Taskiran, C. and Himmetoglu, O. (2005) Primary Omental Pregnancy: Case Report. Human Reproduction, 20, 807-809. http://dx.doi.org/10.1093/humrep/deh683

[6] Daniel, N., Bashir, B., Ibrahim, A. and Swati, S. (2014) A 26-Year-Old Retained Demised Abdominal Pregnancy Presenting with Umbilical Fistula. Case Reports in Obstetrics and Gynecology, Article ID: 932525.

[7] Opare-Addo, H.S. and Deganus, S. (2000) Advanced Abdominal Pregnancy: A Study of 13 Consecutive Cases Seen in 1993 and 1994 at Komfo Anokye Teaching Hospital, Kumasi, Ghana. African Journal of Reproductive Health, 4, $28-$ 39. http://dx.doi.org/10.2307/3583240

[8] Atrash, H.K., Friede, A. and Hogue, C. (1987) Abdominal Pregnancy in the United States: Frequency and Maternal Mortality. Obstetrics and Gynecology, 69, 333-337.

[9] Nnadi, D., Nwobodo, E. and Ekele, B. (2012) Abdominal Pregnancy in Usmanu Dan-Fodiyo University Teaching Hospital, Sokoto: A 10-Year Review. Journal of Basic and Clinical Reproductive Sciences, 1, 34-37. http://dx.doi.org/10.4103/2278-960X.104294

[10] Sunday-Adeoye, I., Twomey, D., Egwuatu, E.V. and Okonta, P.I. (2011) A 30-Year Review of Advanced Abdominal Pregnancy at the Mater Misericordiae Hospital, Afikpo, Southeastern Nigeria (1976-2006). Archives of Gynecology and Obstetrics, 283, 19-24. http://dx.doi.org/10.1007/s00404-009-1260-4

[11] Fouelifack, F.Y., Fouogue, J.T., Fouedjio, J.H. and Sando, Z. (2014) Viable Abdominal Pregnancy: A Case Report in Yaoundé (Cameroon). The Pan African Medical Journal, 18, 181.

[12] Sarwat, A. and Nadia, A. (2011) Abdominal Pregnancy: A Diagnostic Dilemma. The Professional Medical Journal, 18, 479-484.

[13] Gayer, G. (2012) Abdominal Ectopic Pregnancy. New England Journal of Medicine, 367, 2334. http://dx.doi.org/10.1056/NEJMicm1111814

[14] Aliyu, L.D. and Ashimi, A.O. (2013) A Multicentre Study of Advanced Abdominal Pregnancy: A Review of Six Cases in Low Resource Settings. European Journal of Obstetrics \& Gynecology and Reproductive Biology, 170, 33-38. www.elsevier.com/locate/ejogrb

[15] Onan, M.A., Turp, A.B., Saltik, A., Akyurek, N., Taskiran, C. and Himmetoglu, O. (2005) Primary Omental Pregnancy: Case Report. Human Reproduction, 20, 807-809. http://dx.doi.org/10.1093/humrep/deh683

[16] Varma, R., Mascarenhas, R. and Jame, D. (2003) Successful Outcome of Advanced Abdominal Pregnancy with Exclusive Omental Insertion. Ultrasound in Obstetrics and Gynecology, 21, 192-194. http://dx.doi.org/10.1002/uog.25

[17] Tromans, P.M., Coulson, R. and Lobb, M. (1984) Abdominal Pregnancy Associated with Extremely Elevated Serum Alpha-Fetoprotein: Case Report. BJOG: An International Journal of Obstetrics and Gynaecology, 91, 296-298. http://dx.doi.org/10.1111/j.1471-0528.1984.tb04773.x

[18] Morita, Y., Tutsumi, O., Kuramochi, K., Momoeda, M., Yoshikawa, H. and Taketani, Y. (1996) Successful Laparos- 
copic Management of Primary Abdominal Pregnancy. Human Reproduction, 11, 2546-2547. http://dx.doi.org/10.1093/oxfordjournals.humrep.a019157

[19] Jazayeri, A., Davis, T.A. and Contreras, D.N. (2002) Diagnosis and Management of Abdominal Pregnancy: A Case Report. The Journal of Reproductive Medicine, 47, 1047-1049.

[20] Rahman, M.S., Al-Suleiman, S., Rahman, J. and Al-Sibai, M.H. (1982) Advanced Abdominal Pregnancy-Observations in 10 Cases. Obstetrics Gynecology, 59, 366-372.

[21] Varma, R., Mascarenhas, R. and Jame, D. (2003) Successful Outcome of Advanced Abdominal Pregnancy with Exclusive Omental Insertion. Ultrasound in Obstetrics and Gynecology, 21, 192-194. http://dx.doi.org/10.1002/uog.25

[22] Ekele, B.A., Ahmed, Y., Nnadi, D. and Ishaku, K. (2005) Abdominal Pregnancy: Ultrasound Diagnosis Aided by the Balloon of a Foley Catheter. Acta Obstetricia et Gynecologica Scandinavica, 84, 701-702. http://dx.doi.org/10.1111/j.0001-6349.2005.0383a.x

[23] Oriaifo, N., Njoku, A.I., Oriaifo, S.E. and Oriaifo, M.O. (2014) Adjunctive Use of Methotrexate in the Management of Advanced Abdominal Pregnancy: A Case Report and Literature Review. International Research Journal of Pharmacy and Pharmacology, 4, 18-21.

[24] Huang, K., Song, L., Wang, L., Gao, Z., Meng, Y. and Lu, Y. (2014) Advanced Abdominal Pregnancy: An Increasingly Challenging Clinical Concern for Obstetricians. International Journal of Clinical and Experimental Pathology, 7, 5461-5472.

[25] Pieh-Holder, K.L., Scardo, J.A. and Costello, D.H. (2012) Lactogenesis Failure Following Successful Delivery of Advanced Abdominal Pregnancy. Breastfeeding Medicine, 7, 543-546. http://dx.doi.org/10.1089/bfm.2011.0131

[26] Zinger, M. and Rosenfeld, D. (2001) Failed Treatment of Abdominal Pregnancy with Methotrexate: A Case Report. Journal of Reproductive Medicine, 46, 392-394.

[27] Ginath, S., Malinger, A.G., Golan, A., Shahmurov, A.M. and Glezerman, B.M. (2000) Successful Laparoscopic Treatment of a Ruptured Primary Abdominal Pregnancy. Fertility and Sterility, 74, 601-602. http://dx.doi.org/10.1016/s0015-0282(00)00686-5

[28] Kelly, H., Harvey, D. and Moll, S. (2006) A Cautionary Tale: Fatal Outcome of Methotrexate Therapy Given for Management of Ectopic Pregnancy. Obstetrics \& Gynecology, 107, 439-441. http://dx.doi.org/10.1097/01.aog.0000172374.72125.3e

[29] Oriaifo, N., Njoku, A.I., Oriaifo, S.E. and Oriaifo, M.O. (2014) Adjunctive Use of Methotrexate in the Management of Advanced Abdominal Pregnancy: A Case Report and Literature Review. International Research Journal of Pharmacy and Pharmacology, 4, 18-21.

[30] Daniel, N., Bashir, B., Ibrahim, A. and Swati, S. (2014) A 26-Year-Old Retained Demised Abdominal Pregnancy Presenting with Umbilical Fistula. Case Reports in Obstetrics and Gynecology, 2014, Article ID: 932525.

[31] Mekki, Y., Gilles, J.M., Mendez, L. and O’Sullivan, M.J. (1998) Abdominal Pregnancy: To Remove or Not to Remove the Placenta. Primary Care Update for OB/GYNS, 5, 192. http://dx.doi.org/10.1016/S1068-607X(98)00118-8

[32] Atrash, H.K., Friede, A. and Hogue, C.J. (1987) Abdominal Pregnancy in the United States: Frequency and Mortality. Obstetrics Gynecology, 63, 333-337.

[33] Abdullahi, H.M., Yakasai, I.A., Zakari, M. and Shuaibu, S.D. (2013) Late Presentation of Advanced Abdominal Pregnancy with Live Baby: A Case Report and Literature Review. Nigerian Journal of Basic and Clinical Sciences, 10, 2528. http://www.njbcs.net/text.asp?2013/10/1/25/117242

[34] National Population Commission (NPC) (Nigeria) and ICF Macro (2009) Nigeria Demographic and Health Survey 2008. National Population Commission and ICF Macro, Abuja, 83.

[35] Sunday-Adeoye, I., Twomey, D., Egwuatu, E.V. and Okonta, P.I. (2011) A 30-Year Review of Advanced Abdominal Pregnancy at the Mater Misericordiae Hospital, Afikpo, Southeastern Nigeria (1976-2006). Archives of Gynecology and Obstetrics, 283, 19-24. http://dx.doi.org/10.1007/s00404-009-1260-4

[36] Lampe, L.G. (2008) Long-Term Follow-Up after Abdominal Pregnancy. European Journal of Obstetrics \& Gynecology and Reproductive Biology, 137, 247-248. http://dx.doi.org/10.1016/j.ejogrb.2006.11.023 